\title{
Analysis of Morphologic and Morphometric Parameters of Human Mandible
}

\author{
Riya Narwani ${ }^{1}$, Vijaylaxmi \\ ${ }^{1}$ Professor, Department of Anatomy, SMS Medical College, Jaipur, Rajasthan, India, ${ }^{2}$ Assistant Professor, Department of Anatomy, SMS Medical College, Jaipur, \\ Rajasthan, India.
}

\section{Abstract}

Background: Mandible is the largest, strongest and movable part of the skull. Mandible identification is important in medicolegal and anthropological work. Hence; we assessed morphologic and morphometric parameters of human mandible. Subjects and Methods: A total of 25 human mandibles were analyzed in the present study. Only those mandibles were included in the present study for which all the demographic data was available. Among these 25 human mandibles, 13 were of females while the remaining 12 were of males. Various morphologic features included were: Breadth of the ramus, Bicondylar width, and Height of the mandible. All the results were recorded in Microsoft excel sheet and were analysed by SPSS software. Results: Mean breadth of the ramus among males was found to be $3.58 \mathrm{~cm}$ while among females was found to be $3.36 \mathrm{~cm}$. Mean bicondylar width among males was found to be $11.8 \mathrm{~cm}$ while among females was found to be $10.5 \mathrm{~cm}$. Mean height of the mandible among males was found to be $7.9 \mathrm{~cm}$ while among females was found to be $7.1 \mathrm{~cm}$. Morphologic and morphometric parameters were found to be significantly higher among make mandible in comparison to females mandibles. Conclusion: Sexual dimorphism is exhibited by mandible bone, and therefore, can be utilized for assessment of both gender and population.

Keywords: Mandible, Morphometric, Morphologic.

Corresponding Author: Dr. Riya Narwani, Professor, Department of Anatomy, SMS Medical College, Jaipur, Rajasthan, India.

Received: May 2019

Accepted: May 2019

\section{Introduction}

Mandible is the largest, strongest and movable part of the skull. Mandible identification is important in medicolegal and anthropological work. ${ }^{[1,2]}$ The teeth along with skull are best preserved part of human remains. Sex can be more accurately determined after the attainment of puberty. The differences are well marked in bony pelvis and skull. Mandible next to the pelvis in human remains will help us in identification of age, sex and race. ${ }^{[3,4]}$

There have been previous studies to determine sex from the mandible, the shape of the mandible condyle allows it to elevate and depress to open and close the mouth. As the mouth is opened and closed, speech is also produced by the mandible. It varies for male and female. ${ }^{[5,6]}$ Hence; under the light of above mentioned data, we planned the present study to assess morphologic and morphometric parameters of human mandible.

\section{Subjects and Methods}

The present study was conducted in the Department of Anatomy, SMS Medical College, Jaipur, Rajasthan (India) and it included assessment of morphologic and morphometric parameters of human mandible. Ethical approval was obtained from institutional ethical committee. A total of 25 human mandibles were analyzed in the present study. Only those mandibles were included in the present study for which all the demographic data was available. Among these 25 human mandibles, 13 were of females while the remaining 12 were of males. Various morphologic features included were:

- Breadth of the ramus,

- Bicondylar width, and

- Height of the mandible

Criteria described previously in the literature were used for defining this morphologic parameters. ${ }^{[7-10]}$ Separate recording of all these parameters was done among males and females. All the results were recorded in Microsoft excel sheet and were analysed by SPSS software. Chisquare test was used for assessment of level of significance. $\mathrm{P}$ - value of less than 0.05 was taken as significant.

\section{Results}

In the present study, a total of 25 mandibles were analyzed. Among these 25 mandibles, 12 were of males while the remaining 13 were of females. Rounded chin was seen in 2 males and 10 females while square chin was seen in 10 males and 3 females. Significant results were obtained while comparing the distribution of chin types among mandibles divided on the basis of gender. Mean breadth of the ramus among males was found to be $3.58 \mathrm{~cm}$ while among females was found to be $3.36 \mathrm{~cm}$. Mean bicondylar 
width among males was found to be $11.8 \mathrm{~cm}$ while among females was found to be $10.5 \mathrm{~cm}$. Mean height of the mandible among males was found to be $7.9 \mathrm{~cm}$ while among females was found to be $7.1 \mathrm{~cm}$. Morphologic and morphometric parameters were found to be significantly higher among make mandible in comparison to females mandibles.

Table 1: Rounded and square chin in different genders

\begin{tabular}{|l|l|l|l|}
\hline Gender & Rounded chin & Square chin & p- value \\
\hline Males & 2 & 10 & 0.02 \\
\hline Females & 10 & 3 & (Significant) \\
\hline
\end{tabular}

Table 2: Comparison of morphologic and morphometric parameters among males and females

\begin{tabular}{|l|l|l|l|}
\hline $\begin{array}{l}\text { Morphologic and } \\
\text { morphometric } \\
\text { parameters }\end{array}$ & $\begin{array}{l}\text { Males } \\
\text { (Mean) }\end{array}$ & $\begin{array}{l}\text { Females } \\
\text { (Mean) }\end{array}$ & p- value \\
\hline $\begin{array}{l}\text { Breadth of the ramus } \\
(\mathrm{cm})\end{array}$ & 3.58 & 3.36 & $\begin{array}{l}0.00 \\
\text { (Significant) }\end{array}$ \\
\hline Bicondylar width $(\mathrm{cm})$ & 11.8 & 10.5 & $\begin{array}{l}0.00 \\
\text { (Significant) }\end{array}$ \\
\hline $\begin{array}{l}\text { Height of the mandible } \\
(\mathrm{cm})\end{array}$ & 7.9 & 7.1 & $\begin{array}{l}0.00 \\
\text { (Significant) }\end{array}$ \\
\hline
\end{tabular}

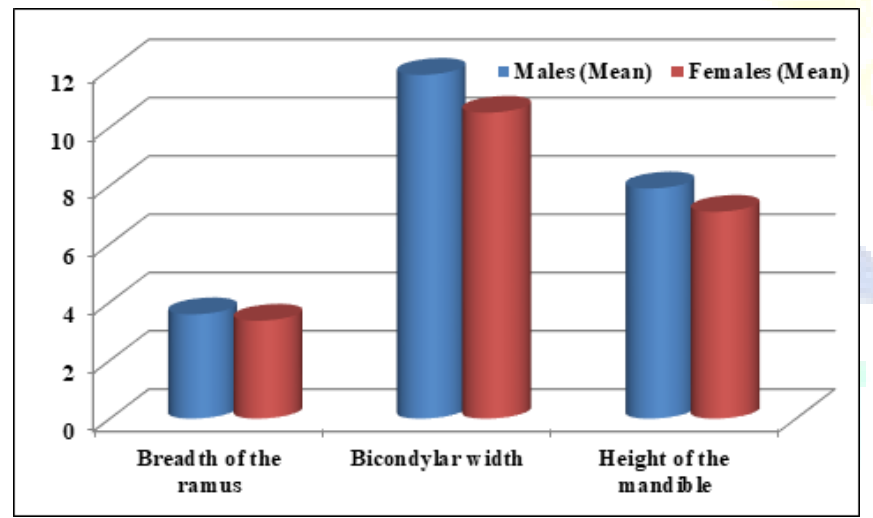

Figure 1: Morphologic and morphometric parameters among males and females

\section{Discussion}

Mandible is the largest, strongest, and lowest bone in the human face. It is the sexually dimorphic bone of skull. Sex of an unknown individual is determined based on the morphology and metric features of skull and mandible. Mandible is the most durable and sexually dimorphic bone of the skull. Sexual dimorphism is shown in stages of mandibular development. Sex determination of bone is very important part of the study in anthropology and forensic science. Among human bones, the pelvis and skull are the most reliable source for the determination of sex. In the absence of complete pelvis, the mandible becomes important for the determination of sex. ${ }^{[7-9]}$

In the present study, a total of 25 mandibles were analyzed. Among these 25 mandibles, 12 were of males while the remaining 13 were of females. Rounded chin was seen in 2 males and 10 females while square chin was seen in 10 males and 3 females. Significant results were obtained while comparing the distribution of chin types among mandibles divided on the basis of gender. Kumar MP et al collected the human mandible bones $(\mathrm{N}=80)$ from the department of Anatomy, SVIMS university and around the Tirupati region to study the morphological and morphometric features by using 22 different parameters. Among 22 parameters Six dominating parameters that possibly explain the nature of the mandible are height of the ramus, body thickness, anthropometric arch width, inter incisor width, mandibular index and mandibular angle are useful to determine the unknown sex of the mandible upto an extent of $75.2 \%$ in south Indian population. The incidence of the above mentioned sex determination parameters considered together and treated statistically. The present study reveals that the mandible of unknown gender can be sexed to the extent of $75 \%$ accuracy by six dominating parameters and not to consider these for complete sex determination of the mandible bone in osteometric studies. ${ }^{[10]}$

The stages of mandibular development, growth rates, and its duration are distinctly different in both the sexes so it is helpful in determining the sex. In addition, masticatory forces are different for males and females, which influence the shape of the ramus and the mental foramen. In general, the male mandibles are large when compared to the female mandible. The outer appearance of male mandible is usually irregular comparing to that of the female. The comparison of both sexes is significant in the current study, the values for the metric parameters were found to be higher in males as compared to females. ${ }^{[9-11]}$

In the present study, mean breadth of the ramus among males was found to be $3.58 \mathrm{~cm}$ while among females was found to be $3.36 \mathrm{~cm}$. Mean bicondylar width among males was found to be $11.8 \mathrm{~cm}$ while among females was found to be $10.5 \mathrm{~cm}$. Mean height of the mandible among males was found to be $7.9 \mathrm{~cm}$ while among females was found to be $7.1 \mathrm{~cm}$. Morphologic and morphometric parameters were found to be significantly higher among make mandible in comparison to females mandibles. Yuvashree CS et al determined the sex of unknown human adult mandible using metrical parameters. A random collection of undamaged human adult mandibles of South Indian population at the Department of Anatomy, Saveetha Dental College, Chennai, was subjected to metrical parameters such as bigonial breadth, bicondylar breadth, and mandibular length and also ramus height as well as the shape of chin to determine their sex. The mean values of all the metric parameters were higher in males than that of females. The difference is significant for all kind of metric parameters. It is concluded that a morphological and morphometric parameters are very helpful to determine the sex of the mandible. ${ }^{[11]}$

\section{Conclusion}

Under the light of above obtained data, the authors conclude 
that sexual dimorphism is exhibited by mandible bone, and therefore, can be utilized for assessment of both gender and population.

\section{References}

1. Singh R, Mishra SR, Sushobhana K, Passey J, Kumar P, Singh S, et al.2015. Sexual dimorphism in adult human mandible of North Indian origin. Forensic Med Anat Res 2015;3:82-8.

2. Mbajiorgu FE. A pilot study of the mandibular angle in black Zimbabweans. Cent Afr J Med 1996;42:285-7.

3. Rai R, Ranade AV, et al. A pilot study of the mandibular angle and ramus in India population. Int J Morphol 2007;25:353-6.

4. Thakur KC, Choudhary AK, Jain SK, Kumar L. Racial architecture of human mandible-an anthropological study. J Evol Med Dent Sci 2013;2:4177-88
5. Krogman WM, Iscan MY. The Human Skeleton in Forensic Medicine. 2nd ed. Springfield: Charles C Thomas; 2015.

6. Giles E, Elliot O. Sex Determination by Discriminant Function Analysis of the mandible. American Journal of Physical Anthropology 1963;22:129-35.

7. Tedeshi. Radiological examination sex determination of skull. Forensic medicine Journal 1977;2:1119-23

8. Saini V. Metric study of fragmentary mandibles in a North Indian population. Bull Int Assoc Paleodontol 2013;7:157-62.

9. Fabian FM, Mpembeni R. Sexual dimorphism in the mandibles of a homogenous black population of Tanzania. Tanzan J Sci 2002;28:4754.

10. Kumar MP, Lokanadham S. Sex determination \& morphometric parameters of human mandible. Int J Res Med Sci 2013;1:93-6.

11. Yuvashree CS, Thenmozhi MS. Morphological and morphometric analysis of mandible bone for determination of sex. Drug Invention Today.2018; 10(1): 2813-18.

Copyright: (C) the author(s), 2019. It is an open-access article distributed under the terms of the Creative Commons Attribution License (CC BY 4.0), which permits authors to retain ownership of the copyright for their content, and allow anyone to download, reuse, reprint, modify, distribute and/or copy the content as long as the original authors and source are cited.

How to cite this article: Narwani R, Vijaylaxmi. Analysis of Morphologic and Morphometric Parameters of Human Mandible. Asian J. Med. Res. 2019;8(2):AT01-AT03.

DOI: dx.doi.org/10.21276/ajmr.2019.8.2.AT1

Source of Support: Nil, Conflict of Interest: None declared. 